\title{
Os bastidores da produção de fogos de artifício em Santo Antônio do Monte: degradação das condições de trabalho e saúde dos pirotecnistas ${ }^{1}$
}

\author{
Carlos Eduardo Carrusca Vieira², Ana Cláudia de Oliveira ${ }^{3}$, \\ Ionára Alves da Silva ${ }^{3}$ e Rafaela Isabel Couto ${ }^{3}$ \\ Pontifícia Universidade Católica de Minas Gerais (Arcos, MG)
}

\begin{abstract}
A cidade de Santo Antônio do Monte é considerada o 2o maior polo mundial de produção de fogos de artifício, sendo a pirotecnia a principal atividade econômica da região. Entretanto, o trabalho na indústria pirotécnica tem suscitado sérias preocupações das entidades sindicais e dos pesquisadores, bem como dos trabalhadores e suas famílias. Os acidentes de trabalho nesse setor são, geralmente, fatais ou mutilantes, havendo, ainda, registros de doenças relacionadas ao trabalho. Por isso, neste estudo almejou-se analisar as repercussões do processo de produção de fogos de artifício sobre a saúde e segurança desses trabalhadores. Os estudos da Psicopatologia do Trabalho e da tradição francesa de análise ergonômica constituíram as principais referências deste estudo. Para a realização desta pesquisa, utilizou-se uma estratégia metodológica pluridimensional, que reuniu e articulou dados estatísticos, empíricos (fatos clínicos, relatos, observações) e documentais. Os resultados revelam que os trabalhadores estão sujeitos a acidentes decorrentes do exercício de funções para as quais não foram adequadamente treinados, bem como a uma atividade penosa e nociva, geradora de lesões por esforço repetitivo (LERs) e doenças osteomusculares relacionadas ao trabalho. As mulheres que trabalham nesse setor também enfrentam o assédio sexual praticado por prepostos dos empregadores.
\end{abstract}

Palavras-chave: Saúde mental e trabalho, Ergonomia da atividade, Clínica da atividade, Pirotecnia, Psicologia do trabalho.

The backstage of fireworks production in Santo Antonio do Monte: notes on the degradation of the pyrotechnists work conditions and health

The town of Santo Antonio do Monte is deemed to be the 2nd largest center of fireworks production in the world, and pyrotechnics is the region's main economic activity. However, the work in the pyrotechnic industry has raised serious concerns from labor unions and researchers, as well as the workers and their families. Labor accidents in this sector are usually fatal or mutilating, and there're also reports of labor-related diseases. Thus, this study aimed to analyze the repercussions of the fireworks production process on these workers' health and safety. Studies on the Psychopathology of Work and those based on the French tradition of ergonomic analysis provided the main references for this study. To carry out this research, we used a pluridimensional methodological strategy, which gathered and connected statistical, empirical (clinical facts, reports, observations), and documental data. The results show that workers are exposed to accidents resulting from the performance of jobs for which they haven't been properly trained, as well as to a painful and harmful activity, which causes repetitive strain injuries (RSIs) and workrelated musculoskeletal diseases. Women who work in this sector also face sexual harassment practiced by their employer's representatives.

Keywords: Mental health and work, Ergonomics of the activity, Activity Clinics, Pyrotechnics, Work Psychology.

\footnotetext{
1 Agradecemos ao Fundo de Incentivo à Pesquisa da Pontifícia Universidade Católica de Minas Gerais (PUC Minas), que contribuiu para a realização desta pesquisa por meio do financiamento das bolsas de iniciação científica; ao Sindicato dos Trabalhadores de Fogos de Artifício de Santo Antônio do Monte e aos seus dirigentes, que não pouparam esforços para que esta pesquisa pudesse ser realizada; e, em especial, aos trabalhadores do setor pirotécnico que participaram deste estudo, investindo seu tempo e seus afetos no relato de seus dramas profissionais.
}

2 Psicólogo. Professor da PUC Minas. Mestre e doutorando em Psicologia na Universidade Federal de Minas Gerais (UFMG).

3 Psicólogas. Graduadas em Psicologia pela PUC Minas. 
$\mathrm{N}$ o Brasil, a história dos artigos pirotécnicos está ligada a Santo Antônio do Monte, cidade mineira onde tudo começou ${ }^{4}$. Ainda em 1859, os irmãos Joaquim Antônio da Silva e Luiz Mezêncio da Silva produziam pólvora e fabricavam de forma artesanal artefatos pirotécnicos (Associação Brasileira de Pirotecnia, 2010). Entretanto, desde 1945, a partir da fundação da primeira indústria pirotécnica na cidade, a expansão das fábricas tem sido expressiva e os barracões, locais onde esses artigos são produzidos, são ocupados em grande parte por trabalhadores dessa cidade (Santos, 2007).

Santo Antônio do Monte está situada na região Centro-Oeste de Minas Gerais. Ela é considerada o segundo maior polo mundial de produção de fogos de artifício, perdendo apenas para a principal região produtora da China (Associação Brasileira de Pirotecnia, 2010). Com uma população aproximada de 30 mil habitantes (Prefeitura Municipal de Santo Antônio do Monte, 2010), a cidade abrange cerca de 45 empresas desse ramo, que geram, no mínimo, 6.600 empregos diretos e indiretos, sendo a pirotecnia a principal atividade econômica da região (Santos, 2007).

A indústria pirotécnica é responsável pela confecção de uma diversidade de produtos desse gênero, comercializados dentro e fora do Brasil. Entretanto, o trabalho na indústria pirotécnica tem suscitado sérias preocupações dos dirigentes sindicais, pesquisadores, trabalhadores e suas famílias, pois, segundo Trivelato e Barreto (2008), os fogos de artifício são artefatos perigosos e a explosão é o principal perigo inerente à sua fabricação e uso.

Justamente em função do elevado índice de acidentes de trabalho decorrentes da produção desses artigos, em 1998, a Delegacia Regional do Trabalho de Minas Gerais realizou inspeções em algumas fábricas de fogos de artifício (Trivelato \& Barreto, 2008). Elas não foram suficientes para reduzir o número de acidentes, mas conduziram à realização de um estudo exploratório, que serviu de base para uma intervenção realizada posteriormente por esse órgão, em parceria com o Ministério Público do Trabalho (MPT) e a Fundação Jorge Duprat Figueiredo de Segurança e Medicina do Trabalho (Fundacentro) de Minas Gerais (Trivelato \& Barreto, 2008). Entre os principais problemas identificados por esse estudo foram constatados os seguintes:

[...] os empregadores não viam os custos com segurança como um investimento; os profissionais pirotécnicos desconheciam as características perigosas das misturas intermediárias e produtos finais que manuseavam e, portanto, não sabiam como prevenir explosões; inexistiam programas de controle da qualidade e gestão de riscos implementados; havia aceitação social dos riscos e ocorrência de explosões como fato "normal" ou "inerente ao processo" por todos os membros da comunidade (Trivelato \& Barreto, 2008, p. 3).

Após uma década, teria essa realidade sido modificada substancialmente? Evidências recentes indicam que as condições de trabalho não passaram por melhorias significativas. Ao estudar os acidentes súbitos no setor pirotécnico de Santo Antônio do Monte, Santos (2007) concluiu que a realidade desses trabalhadores é marcada pelo medo, tensão e angústia, ligados tanto aos acidentes de trabalho como ao seu fazer no cotidiano profissional.

Entretanto, mais do que os problemas expostos pelos estudos mencionados, os relatos dos próprios operários mostram que o processo de produção de fogos de artifício e as condições sob as quais se trabalha estão estreitamente relacionadas aos distúrbios de saúde e aos graves

4 A pirotecnia consiste na fabricação de fogos de artifício em geral, designação mais comum dada às "peças pirotécnicas preparadas para transmitir a inflamação a fim de produzir luz, ruído, incêndios ou explosões, e normalmente empregada em festividades" (Ministério do Trabalho e Emprego, 2000a). 
acidentes de trabalho de que são vítimas, alguns destes recentemente noticiados pelos meios de comunicação:

Nesta quinta-feira (29 de julho 2010), três pessoas ficaram feridas em mais uma explosão em uma fábrica de fogos de artifício em Santo Antônio do Monte, na região Centro-Oeste de Minas. Esta foi a segunda explosão registrada só nesta semana. Na terça-feira, um homem de 34 anos morreu depois de ter $85 \%$ do corpo queimado e sofrer várias fraturas. Segundo a Polícia Militar, o acidente desta manhã aconteceu em um dos barracões da fábrica. A explosão atingiu ainda outras partes da indústria, além de danificar casas vizinhas. A perícia ainda não sabe o que causou o problema (Outra explosão com fogos de artifício..., 2011).

Nesse sentido, este estudo teve por objetivo analisar as repercussões do processo de produção de fogos de artifício para a saúde e segurança dos trabalhadores, entendendo que, além do evidente risco de explosões, há outros riscos presentes no processo de produção desses artigos, que precisam ser mais bem identificados, visando à melhoria das condições de trabalho e saúde nesse setor.

\section{Percurso metodológico}

Esta investigação se caracteriza como uma pesquisa descritivo-explicativa, de natureza predominantemente qualitativa ${ }^{5}$ Orientou-se por uma estratégia metodológica pluridimensional, abordagem na qual se reúnem e articulam dados estatísticos, empíricos (fatos clínicos, relatos, observações) e documentais, provenientes de distintas fontes, em um movimento semelhante ao utilizado por Le Guillant (2006), nas pesquisas fundadoras da Psicopatologia do Trabalho. No decorrer deste estudo, foram utilizadas múltiplas técnicas e fontes de evidência, num movimento de confronto constante entre os dados provenientes da pesquisa de campo, pesquisa documental e revisão teórica (Le Guillant, 2006).

Esta pesquisa se fundamenta também na tradição francesa de análise do trabalho, em particular na Ergonomia da Atividade (Guérin, Laville, Daniellou, Duraffourg \& Kerguelen, 2001), o que explica seu interesse pela aproximação das situações reais de trabalho.

Nessa abordagem, pressupõe-se que as condições previstas para realização das tarefas não coincidem com aquelas que o indivíduo encontra em uma situação real de trabalho (Guérin et al., 2001). Entre o que é formalmente solicitado a um trabalhador (trabalho prescrito) e aquilo que ele realmente tem de fazer para garantir a realização dos objetivos pessoais e profissionais (trabalho real) sempre há um intervalo inelutável (Guérin et al., 2001). Por isso, em situação real de trabalho, o trabalhador é convocado a lidar com imprevistos e problemas que não poderiam ser antecipados ou respondidos de forma satisfatória pelos procedimentos padrão (Vieira, Lima \& Barros, 2007).

Assim, em direção a uma abordagem concreta das condições de trabalho e saúde na pirotecnia, realizamos uma pesquisa de campo no período de fevereiro de 2010 a junho de 2011, na qual foram ouvidos 28 trabalhadores e 3 dirigentes do Sindicato dos Trabalhadores de Fogos de Artifício (Sindifogos). O conjunto de participantes deste estudo abrange indivíduos do sexo masculino e feminino, na faixa etária de 25 a 45 anos, que possuem de 2 a 25 anos de experiência na produção de fogos de artifício e trabalham nas diversas etapas da produção desses artigos. Optou-se pela utilização de entrevistas não estruturadas (Minayo, 1994), por se tratar de uma técnica que proporciona maior liberdade ao entrevistado para abordar assuntos

5 A proposta de pesquisa foi registrada e aprovada pelo Comitê de Ética em Pesquisa (CEP) da Pontifícia Universidade Católica de Minas Gerais, em dezembro de 2009. 
pertinentes a um dado fato ou situação. As entrevistas foram gravadas e transcritas, com o consentimento livre e esclarecido dos participantes.

A aproximação ao campo de pesquisa foi realizada em fevereiro de 2010. Nessa ocasião, foram entrevistados o presidente e dois dirigentes do Sindifogos. Seus relatos indicaram que a realidade nas fábricas afrontava os direitos básicos dos trabalhadores e da pessoa, o que sublinhou a importância de se aprofundar a análise das dimensões macrossociais do processo de produção de artigos pirotécnicos. Por isso, foi necessário realizar uma pesquisa documental, que abrangeu as leis, decretos, regulamentos e outros documentos relevantes para entendimento do cenário no qual está inserido o setor pirotécnico.

Posteriormente, os pesquisadores retornaram à entidade sindical para estabelecer o primeiro contato com os trabalhadores. Em função do receio de retaliação manifesto pelos dirigentes sindicais e operários, optou-se por realizar as entrevistas em espaço reservado, sugerido pelo Sindifogos.

A primeira entrevista foi realizada com um grupo de 9 trabalhadores do setor pirotécnico que atuam em diferentes etapas do processo produtivo. Nessa entrevista, eles revelaram problemas ainda mais graves do que aqueles citados pelos dirigentes sindicais, exigindo um olhar mais cuidadoso sobre as diferentes etapas do processo produtivo.

Em seguida, foram realizadas entrevistas com três grupos distintos de trabalhadores e, também, entrevistas individuais com 3 operárias que relataram ter sido vítimas de assédio sexual.

Em uma das entrevistas em grupo, da qual participaram 8 indivíduos, foi utilizada a técnica das verbalizações, que consiste, basicamente, em: convidar o trabalhador a comentar fatos registrados pelos pesquisadores a partir de observação da situação de trabalho e que the são apresentados por meio de anotações, vídeos etc. (Guérin et al., 2001); descrever e explicitar a lógica da ação dos trabalhadores diante de situações reais de trabalho; e levantar questões pertinentes sobre a saúde e segurança no trabalho. Nesse caso, em particular, os participantes foram convidados a emitir verbalizações acerca de situações reais de trabalho da pirotecnia, retratadas em um vídeo exibido pelos pesquisadores, gravado pelas bolsistas de iniciação científica, em conjunto com um grupo de alunas da Pontifícia Universidade Católica de Minas Gerais em Arcos, em uma fábrica de fogos de artifício situada em uma cidade vizinha. Simultaneamente à exibição do vídeo, os trabalhadores teciam comentários sobre sua atividade, explicitando também as etapas e os riscos do processo produtivo. A análise do processo de produção se mostrou novamente um desafio, em função da quantidade de etapas, produtos e materiais empregados na produção pirotécnica e de suas variabilidades. As outras duas entrevistas, realizadas com grupos de 11 trabalhadores cada, almejaram aprofundar a análise dos temas mais recorrentes nos relatos feitos na primeira entrevista.

Nas entrevistas individuais, realizadas com as três trabalhadoras, abordou-se a prática do assédio sexual, mencionada por elas na ocasião do primeiro contato, visando a esclarecer as razões e formas pelas quais o assédio sexual se manifestava nas relações de trabalho, bem como seus impactos sobre a vida dessas mulheres.

De forma complementar, foram analisadas as informações que constam do Anuário Estatístico de Acidentes de Trabalho, do Ministério da Previdência Social (2006; 2007; 2008) e 35 Comunicações de Acidente de Trabalho (CATs) arquivadas no Sindifogos, visando a identificar os acidentes e distúrbios de saúde mais frequentes, a etapa no processo produtivo em que ocorreram e as explicações mais comuns, dadas pelas próprias fábricas de fogos de artifício, para esses incidentes.

Em função da frequência dos acidentes de trabalho nesse setor, realizou-se uma entrevista em grupo com oito operários que enfrentaram situações desse tipo em sua trajetória 
profissional na pirotecnia, com o objetivo de identificar os fatores determinantes e de risco desses incidentes.

Em virtude da gama de questões levantadas, foi preciso delimitar os temas mais significativos e recorrentes nos relatos dos trabalhadores, privilegiando uma visão panorâmica dos problemas que enfrentam em seu cotidiano profissional. Evidentemente, isso limitou a profundidade deste estudo e, em particular, da análise de cada uma das etapas do processo produtivo, mas possibilitou um olhar amplo sobre as condições políticas, materiais e ambientais de trabalho, as formas de gestão e organização do trabalho, o assédio sexual, os acidentes e doenças relacionadas à sua atividade produtiva. Os dados obtidos por meio das entrevistas foram, dessa forma, agrupados em categorias que, a nosso ver, representam dimensões relevantes para a compreensão das condições de trabalho, saúde e segurança existentes nesse setor. Finalmente, procedeu-se à análise do conteúdo dos depoimentos, visando a aprofundar a investigação das questões neles presentes.

Os resultados apresentados neste estudo se referem às condições de trabalho de, aproximadamente, seis fábricas de artigos pirotécnicos, não podendo, portanto, ser generalizados sem a devida análise das situações existentes nas demais empresas.

\section{Resultados}

\section{Os bastidores políticos da produção de fogos de artifício em Santo Antônio do Monte}

$\mathrm{Na}$ visão dos dirigentes sindicais, a atuação do Sindifogos na defesa dos direitos dos trabalhadores e na luta por melhores condições de trabalho ainda é pouco eficaz. A frágil mobilização dessa categoria profissional, tanto no que se refere à filiação sindical como à participação nas greves, deve-se, segundo os entrevistados, às intensas pressões feitas pelo patronato, intimidações que se manifestam de formas variadas.

Os trabalhadores relatam sofrer ameaças em relação ao emprego e ser advertidos quando se associam ao Sindifogos. Muitos receiam participar das mobilizações sindicais, greves e assembleias e reivindicar melhores condições de trabalho e salário, temendo uma reação patronal. As manobras políticas realizadas pelo empresariado fragilizam a mobilização e as ações de organização sindical, sendo a ameaça em relação ao emprego e aos direitos dos trabalhadores alguns dos principais artifícios utilizados pelo patronato para diluir as ações reivindicatórias.

De acordo com o relato dos trabalhadores entrevistados, os representantes das fábricas chegam a oferecer gratificações àqueles que não aderem às greves. Os que participam dos movimentos grevistas dizem sofrer duramente a pressão patronal, são taxados de catimbeiros e ficam com o nome sujo na praça, como afirma uma entrevistada: "Catimbeiro quer dizer quando você reclama pelos seus direitos aqui, quando você procura fazer valer os seus direitos, você é uma pessoa catimbeira, pra eles você não serve...”.

No contexto das relações de trabalho, parece ter se estabelecido uma cultura contrarreivindicatória, fortemente sustentada pelo patronato. A análise da Convenção Coletiva de Trabalho (CCT) estabelecida entre o Sindifogos e o Sindicato Patronal permite vislumbrála. Ela evidencia a fragilidade da entidade de representação dos trabalhadores em face do poder dos grupos empresariais que comandam o setor. A CCT se limita a repetir determinações já previstas na Consolidação das Leis do Trabalho (CLT), sem incorporar ganhos ou benefícios reais aos trabalhadores. Esse é o caso, por exemplo, das cláusulas que tratam sobre a constituição das Comissões Internas de Prevenção de Acidentes (CIPAs), da licença- 
maternidade, da obrigatoriedade da emissão da Comunicação de Acidente de Trabalho (CAT) e, até mesmo, da disponibilidade de água potável para os trabalhadores. Os depoimentos dos operários são decisivos a esse respeito e mostram que eles têm pouco poder de decisão na determinação de suas condições de trabalho, mesmo em conjunto com o Sindifogos. Evidenciase, assim, a desproporcionalidade de forças nos embates entre classes antagônicas, representadas por patrões e empregados, e que se manifestam de modo concreto no cotidiano de trabalho nas fábricas.

O desinteresse das empresas na melhoria das condições de trabalho e saúde também é um aspecto marcante da realidade desses profissionais e aparece com frequência no depoimento dos entrevistados: "O povo de Santo Antônio do Monte, principalmente o trabalhador de fábrica, eles estão adoecendo, e pra empresa se você algum dia sofre uma queda na sua produção, pra fábrica não interessa $[\ldots] "$.

A despeito das normatizações dos órgãos competentes, os operários se sentem desprotegidos em face do poder dos empresários do setor, uma vez que a ação dos órgãos de fiscalização não tem contribuído para assegurar condições de trabalho seguras, como afirma uma das entrevistadas:

Quando o Ministério do Trabalho vem, são os encarregados, os donos da fábrica que vão apresentar a fábrica pro fiscal e [este] nada de olhar os trabalhadores, como que é a situação... Aí, um encarregado vai na frente escondendo o material no meio do mato e o outro vai apresentando o setor pra ele, enquanto isso o outro vem atrás colocando de novo, tirando do mato e jogando pro setor de novo.

[Que tipo de material que eles escondem?]

É muita pólvora no cargueiro. Os funcionários sem carteira [assinada] eles vão tirando e levam pra esconder no meio do mato... [Na] hora que eles [os fiscais] voltam [pra] trás, eles [os trabalhadores sem carteira assinada], [os responsáveis] mandam eles irem lá pra outro setor, ficar trancados dentro do barracão, lá. Aí eles [patrões, encarregados] falam [para os fiscais]: não... nesse aí não tem nada trancado, não. Aí, os funcionários tão tudo trancado no barracão lá, [eles] põem dentro do banheiro.

Nessa direção, pretende-se descrever e analisar alguns dos principais problemas e dificuldades vividas pelos trabalhadores do pirotécnico em seu cotidiano profissional.

\section{As condições materiais e ambientais de trabalho}

A concessão do registro e a fiscalização do funcionamento das fábricas de fogos de artifício são atribuições do Exército Brasileiro. Para funcionar, as fábricas têm de satisfazer severas normas de segurança, que estabelecem os parâmetros para armazenamento, fabricação, aquisição e transporte de produtos controlados, como é o caso das peças pirotécnicas (Ministério do Trabalho e Emprego, 2000a).

Em razão do Decreto n. 3.665, de 20 de novembro de 2000 (Regulamento para a Fiscalização de Produtos Controlados) (Brasil, 2000) e da Norma Regulamentadora n. 19 (Explosivos), do Ministério do Trabalho e Emprego (2000b), as fábricas de fogos de artifício devem ser instaladas na zona rural, distantes de edificações e habitações urbanas. Os barracões e cargueiros, respectivamente, onde se produzem e armazenam os explosivos e produtos pirotécnicos, também devem ficar distantes entre si.

As condições ambientais e materiais de trabalho no setor pirotécnico se caracterizam pela precariedade. Os barracões são ambientes muitas vezes pequenos, pouco iluminados e abafados. O sistema de saneamento é artesanal, e às vezes apresenta problemas para a eliminação de resíduos químicos da produção, o que leva à contaminação da vegetação local e, 
em certos casos, do leito de rios. A higiene precária dos locais destinados à alimentação e a má qualidade das refeições oferecidas pelas fábricas também são fonte de insatisfação por parte dos trabalhadores. Os relatos de alguns operários retratam essa situação:

Não tem um armário pra guardar os mantimentos, prato, colher, fica tudo solto. Tem rato lá dentro, às vezes gato pra todo lado, cachorro todo lado, eles guardam mantimento lá, e tem cachorro pra todo lado, rato pra todo lado, barata [...].

O setor de cartonagem é o local onde se realizam as primeiras etapas da produção dos fogos de artifício, em particular, a confecção de canudos e da parte externa dos artigos pirotécnicos. Diferencia-se dos demais na medida em que os operários não chegam a manusear materiais explosivos.

$\mathrm{Na}$ etapa de colação, os canudos recebem como base outro canudo, também feito de papel, e que servirá como suporte do artefato e, em seguida, na estopinação, recebem os estopins. Nessas fases, os trabalhadores manuseiam papel e cola e operam máquinas para colar, lixar e cortar os papéis, dando-lhes a consistência e as dimensões adequadas para a confecção dos canudos dos foguetes, com as espoletas.

Nos setores de manipulação da pólvora, os trabalhadores manuseiam as misturas químicas que, no setor de matriz, vão preencher os pequenos tubos que ficarão alojados dentro de cada um dos foguetes. Em particular, os barracões onde se manipula a pólvora branca, considerada a mais perigosa, por sua composição altamente inflamável (Santos, 2007), devem ter no mínimo $12 \mathrm{~m}^{2}$, sendo permitida a permanência de apenas uma pessoa. $O$ piso desse barracão deve ser impermeável e, sobre ele, deve haver uma lâmina d'água com, pelo menos, 10 $\mathrm{cm}$ de profundidade, para evitar explosões decorrentes do contato entre elementos que participam de reações químicas. Os operários devem utilizar botas de borracha que cobrem até a altura do joelho, para não ter contato direto com água carregada com resíduos químicos.

Em todos os setores onde se trabalha com explosivos é proibido utilizar calçados que possam acumular pólvora ou causar um forte atrito com o solo, recomendação que visa a prevenir a contaminação de outros locais por esse produto. $O$ processo de produção dos artigos pirotécnicos é finalizado com a arrematação, momento em que são montados e embalados em caixas.

Conforme foi brevemente exposto, as condições materiais e ambientais da produção de artigos pirotécnicos são precárias e os trabalhadores se encontram desamparados não apenas por seus empregadores, mas, também, pelo poder estatal. Entretanto, os distúrbios de saúde e acidentes de trabalho não se explicam apenas por essas condições, mas também encontram suas raízes no modo de organização e gestão da força de trabalho.

\section{A organização do trabalho e o processo de produção dos fogos de artifício}

A organização do trabalho é a forma pela qual se ordenam e se coordenam as diferentes tarefas necessárias à realização dos objetivos de uma organização ou empresa, implica a divisão do trabalho, uma coordenação entre essas tarefas, uma organização do tempo das variadas funções, que envolvem equipamentos (tecnologia), homens e materiais (Lima, 1997). Mas, a organização do trabalho jamais resulta apenas de um conjunto de decisões isoladas e procedimentos técnicos, pois a maneira "de se organizar um trabalho é um fator social determinado e determinante de uma lógica social" (Assunção, 2003, p. 1015). Por isso, deve-se sempre considerar que as condições de trabalho trazem em si "as marcas de uma relação de forças e dos valores da sociedade em que elas são geradas" (Assunção, 2003, p. 1015). Em nossa sociedade, a organização do trabalho implica, ao mesmo tempo, técnicas de produção e de dominação patronal sobre os trabalhadores (Gorz, 1996). Por meio dela se realiza a finalidade 
primeira da produção capitalista que "nada mais é do que o aumento do capital em si; e tal finalidade, alheia aos trabalhadores, só pode ser realizada por eles, sob coerção (direta ou velada)" (Gorz, 1996, p. 11).

O processo de fabricação dos artigos pirotécnicos é de caráter manufatureiro e se baseia em uma lógica de produção taylorista, marcado pela forte cisão entre a concepção do trabalho e sua execução. A repetitividade do trabalho é referida pelos entrevistados como o traço mais característico de suas tarefas. Eles parecem agir de modo cada vez mais mecânico e intolerável. A divisão das tarefas, o conteúdo e os ritmos de trabalho são rigidamente estabelecidos e fiscalizados pelos encarregados, que circulam pelos pavilhões e barracões onde se produzem os artigos pirotécnicos, impondo que os trabalhadores se ajustem às suas determinações. Em função das longas jornadas de trabalho, da rigidez da organização do trabalho, dos maus-tratos dispensados pelos patrões e encarregados, muitos trabalhadores entrevistados qualificam seu trabalho como um regime de "trabalho escravo". Nesse cenário, a pressão por produtividade e a negação das necessidades básicas dos trabalhadores parece ser uma situação constante nas fábricas, aparecendo de modo explícito no relato dos trabalhadores:

Tem mulher que trabalha com vontade de ir no banheiro, vontade de tomar água, vontade de tudo, porque não pode parar... É só pressão que já vem do encarregado geral, que passa pro encarregado do setor e aí vem a pressão, é a pressão do encarregado geral com o encarregado de setor e um funcionário com o outro, e assim vai.

Você tá preso ali... às vezes, você perde o sono por causa do serviço, por causa da tarefa. Aí, chega no dia lá, prensa a mão e depois num tem mais ela pra trabalhar... isso acontece... [você] fica apavorado.

A dilatação da jornada de trabalho, a intensificação do ritmo de produção e a constante vigilância exercida pelos encarregados, parecem contribuir para o sofrimento dos operários. Entretanto, eles se veem obrigados a se submeter às exigências de produção por medo de perder o emprego ou sofrer perdas financeiras: "Se eu não correr mesmo eu não vou conseguir cumprir a minha tarefa, e se eu não fizer a tarefa vai descontar no meu salário, entendeu?". A vigilância exercida pelos encarregados é, assim, um dos traços mais marcantes da organização e gestão do trabalho dos pirotecnistas, e responde à exigência de acumulação do capital, que se materializa no poder despótico exercido pelos representantes do capital sobre o trabalho (Gorz, 1996).

\section{O assédio sexual no contexto de trabalho}

Em seu manuscrito histórico A situação da classe trabalhadora na Inglaterra, Friedrich Engels (1844/2008) retratou a situação miserável dos operários, durante o período da Revolução Industrial inglesa. Nessa publicação, ele destacou a presença de certos elementos no ambiente de trabalho fabril que favoreciam fortemente a "promiscuidade" nas relações de trabalho.

De acordo esse autor, com a introdução das máquinas, de força hidráulica ou vapor, na produção têxtil, vários trabalhadores, principalmente os homens adultos, foram lançados no desemprego. $O$ trabalho humano na produção têxtil passou a consistir na vigilância das máquinas ou na reparação dos fios que se rompiam, não sendo necessária nesta última tarefa a força física de homens adultos, mas apenas dedos ágeis (Engels, 1844/2008). Assim, a produção têxtil passou a empregar principalmente as mulheres e crianças, pagando-lhes salários inferiores aos dos homens adultos.

Em função dessas circunstâncias, houve uma inversão nos papéis sociais desempenhados por homens e mulheres, que não significou a possibilidade de um desenvolvimento da feminilidade do homem e da virilidade da mulher (Engels, 1844/2008). Ao 
contrário, tratavam-se de circunstâncias constrangedoras que coagiam ambos os sexos a funções sociais distintas e tolhiam "o caráter viril do homem e a feminilidade da mulher, sem oferecer ao homem uma verdadeira feminilidade e à mulher uma verdadeira virilidade..." (Engels, 1844/2008, p. 184) .

A obra de Engels (1844/2008) apresenta exemplos dessa inversão de papéis e os problemas dela decorrentes. $\mathrm{O}$ autor resgata relatórios produzidos por comissões de inspeção de fábricas e depoimentos diversos de operários e defensores dessa "causa operária". Em um deles, uma trabalhadora relata a angústia e as dores nos seios causadas pela permanência forçada nas fábricas, durante uma jornada de trabalho de mais de dez horas, que a impedia de cuidar e amamentar seu filho: "Meus seios me causam dores terríveis e com frequência escorrem a ponto de me deixarem molhada" (Ashley, 1844, citado por Engels, 1844/2008, p. 182).

Além da influência negativa da linguagem "indecente", "corrompida" e "suja" utilizada no ambiente fabril, relatada pelas operárias aos inspetores de fábrica, Engels (1844/2008) destacou a existência de uma prática de exploração sexual das mulheres, vendo na relação de servidão sua principal razão. Para ele, os patrões se veem na condição de gozar do jus primae noctis, o "direito à primeira noite", também conhecido como droit du seigneur, que permitia aos senhores feudais desvirginar as noivas de seus vassalos (Engels, 1844/2008). Assim, sentiam-se os senhores "do corpo e dos encantos de suas operárias" (Engels, 1844/2008, p. 186), sendo que, na maior parte dos casos, a ameaça de demissão era uma razão suficiente "para anular qualquer resistência das jovens que, ademais, não têm muitos motivos para preservar sua castidade" (Engels, 1844/2008, pp. 186-187). A fábrica havia se tornado não apenas a propriedade, mas, ao mesmo tempo, o "harém" dos patrões.

Em se tratando disso, por meio das entrevistas pode-se perceber que a situação nas fábricas de produção de fogos de artifício não é tão diferente dos tempos da Revolução Industrial. Os depoimentos das trabalhadoras evidenciam que elas são alvos do assédio sexual por parte dos encarregados:

Outra coisa que tá terrível aqui, também, é que as mulheres aqui precisam começar a denunciar o assédio sexual. Eu já fui vítima de assédio sexual aqui, sério mesmo, um certo encarregado, eu comecei a trabalhar e ele se aproveitava que a gente é novata... aí, que ele vai lá e faz, ele vai lá e te dá uma cantada... [é] que às vezes ele é muito safado e insatisfeito sexualmente, vai lá e te dá uma cantada. Você é novata... se você não cede ao que ele quer, ele te manda embora.

Então, eles fazem pressão na pessoa dentro do barracão, ali mesmo. Eles chegam... ao invés de falar bom dia, já vão te colocar a mão e da mão no ombro já passa pra sua cintura e da cintura já fica querendo colocar mais em baixo, e você tá com a mão suja de material e pede pra [ele] parar e a pessoa não para. [Você diz] Tira a mão de mim! [E ele responde] Não, que é isso? Você tá nervosa hoje, que 'cê tem? Calma. E já vai te assediando. [Você diz] Eu tô trabalhando, dá licença. Aí eles não param, e ficam fazendo pressão em cima do'cê.

Os encarregados que assediam as trabalhadoras parecem gozar de autonomia suficiente para impor-lhes punições, caso recusem suas propostas:

Ele fala: "nossa você é bonita, você é gostosa", você é isso, você é aquilo. De certa forma eles levantam... entendeu... nas primeiras [vezes] eles levantam sua autoestima e te coloca lá em cima, pra depois já partir pra chantagem mesmo: "ah, vamos em tal lugar comigo, vamos sair comigo, vamos tomar uma cerveja comigo?".

Já teve uma vez que eu tava sozinha dentro do barracão, aí ele entrou e já veio tentando me agarrar, e ele é insistente, não vê que você já deu fora nele, que você já falou que não quer, ele é insistente. Eu tenho vergonha até de falar, mas como é aqui só entre a gente... 
[uma vez] ela [uma colega de trabalho] me falou [a pedido dele] assim: se você não der pra ele, ele vai te mandar embora, se não der pra ele, ele vai te mandar embora.

Por outro lado, aquelas que se submetem são "premiadas" com regalias e privilégios no serviço: "A mulher que tem o relacionamento com o encarregado, ela faz o que quer, escolhe o serviço, manda, recebe o cerão [pagamento] sem ter trabalhado, tem falta e não é descontado, tem umas vantagens que outras pessoas não teriam". A ameaça ao emprego e as pressões por produção estão sempre presentes nas intimidações feitas pelos encarregados que assediam as trabalhadoras.

De acordo com o relato das trabalhadoras, o assédio sexual é frequente nas fábricas e existe uma pressão por parte dos encarregados para que o assunto não seja comentado, como relata uma entrevistada:

Muitas vezes, você trabalha numa fábrica, mas você recebe uma pressão pra não comentar aqui na cidade o que acontece lá dentro, é assim desse jeito.

[Entrevistador: E como que é essa pressão pra você não comentar?]

Ah, eles falam pra você que isso se chama ética, que é falta de ética [comentar fora do trabalho]. Os encarregados mesmo que falam, lá mesmo era proibido... se você chegasse aqui na cidade e contasse o que tava acontecendo lá dentro, aí se chegava lá, você era um linguarudo, fofoqueiro, que [o encarregado] vai mandar embora, vai fazer isso e aquilo...

Em relação a essas reuniões, realizadas pelos encarregados, algumas das entrevistadas afirmam que os próprios funcionários criaram um nome para designá-la, como explicam:

Chama todo mundo, [para dizer que] o que acontece aqui tem que ficar aqui dentro. Mas [essas reuniões acontecem] sem o patrão, essas reuniões são sem o patrão, o patrão muitas vezes nem fica sabendo, eles [trabalhadores] costuma falar $\mathrm{CRG}$ - comida de rabo geral.

[Entrevistadora: CRG - comida de rabo geral, quem nomeou isso?]

Os próprios funcionários, eles colocam CRG, mas é, tipo assim, pra você calar a boca, é pra calar a boca, tanto moral como sexual.

Como se pode perceber, a prática do assédio sexual parece ter sido institucionalizada em algumas das fábricas de fogos de artifício, mas não chega a ser denunciada pelas trabalhadoras às autoridades, por diversas razões, principalmente pelo medo de perder o emprego e pelo constrangimento de falar sobre o assunto.

\section{Os acidentes de trabalho no setor pirotécnico}

No percurso deste estudo, realizou-se também um levantamento de dados sobre os acidentes de trabalho no setor pirotécnico, a partir das informações do Anuário Estatístico de Acidentes de Trabalho (AEAT), do Ministério da Previdência Social, referentes ao período de 2006 a 2008. Os resultados dessas análises indicam que a maior parte dos acidentes de trabalho no setor de fogos de artifício ocorre durante a realização das tarefas ligadas à produção, respondendo por mais de $60 \%$ do total de acidentes nesse setor.

Ao longo da jornada de trabalho, os trabalhadores estão expostos a vários riscos, ergonômicos, psicossociais, químicos e físicos que podem ocasionar acidentes de trabalho. $\mathrm{O}$ primeiro desses fatores de risco é a inadequação do treinamento técnico oferecido aos funcionários para o desempenho das funções, conforme relatado por todos os entrevistados:

Se você for dentro de uma empresa hoje, eles vão virar pro'cê e falar assim: "nós temos um engenheiro de segurança, um engenheiro químico, nós temos técnico de segurança”. É... 
mas o técnico de segurança fica dentro do escritório, o engenheiro químico tá tranquilão... Entendeu? Aí, 'cê vai começar a trabalhar em determinada empresa aí amanhã, aí eles vão dizer assim: "então, vem cá que eu vou te dar um treinamento, eu vou ler pro'cê. 'Cê vai trabalhar com pólvora negra, vai oh: lá 'cê não pode bater, "cê não pode arrastar, "cê não pode deixar cair, 'cê não pode fazer qualquer coisa. Acabou... tchau pro'cê, boa sorte!”. Esse é o treinamento!

Em vez de um treinamento específico, os operários recebem instruções dos técnicos, situação que os deixa à própria sorte, responsáveis por sua própria segurança: "É só na leitura, o resto é a prática sua lá dentro...". A atuação dos engenheiros e técnicos de segurança também é considerada um problema na percepção dos entrevistados, porque não orientam os trabalhadores quanto às medidas que devem tomar para evitar acidentes, tampouco inspecionam os locais de trabalho: "A segurança quem faz é você... a sua segurança quem faz é você quer dizer, [eles estão] se livrando daquilo entendeu? Você que se vire".

Do mesmo modo, as CIPAs são consideradas ineficazes pelos entrevistados, porque não cumprem seus objetivos principais, ou seja, identificar fatores de risco e propor melhorias nas condições de trabalho, saúde e segurança: "A CIPA deles ali, também, é tudo no papel... você fica no seu cargo, mas ninguém faz inspeção no barracão pra ver como que tá a situação, o que tem que melhorar...".

Nos setores onde os operários manipulam produtos perigosos, como a pólvora branca, nem sempre são asseguradas as condições mínimas de segurança, como, por exemplo, a existência de uma lâmina d'água que impeça o atrito dos calçados com os produtos químicos que se alojam no chão.

A forma de gestão da força de trabalho também parece estar relacionada aos acidentes de trabalho. É comum que os operários sejam transferidos para atuar em postos de trabalho que não conhecem: "Ih, você é obrigado, você é obrigado no dia que você entra [a trabalhar em setores diferentes]. Eu não tenho serviço certo, cada dia eu tô num lugar".

Trata-se de uma prática que atende apenas os interesses mais imediatos da produção, sem considerar os riscos a que serão expostos os trabalhadores. Como poderiam gerir as incertezas e dificuldades com que se deparam no cotidiano de trabalho se não contam com a experiência acumulada e, menos ainda, com um coletivo de trabalho experiente com o qual possam partilhar as regras e macetes do ofício ${ }^{6}$ ?

Aqueles que tiveram a oportunidade de sobreviver aos riscos e conseguiram acumular ao longo dos anos experiência de trabalho sabem o quanto ela é fundamental para sua própria segurança. A experiência de trabalho permite aos indivíduos construir esquemas profissionais indispensáveis para enfrentar certas situações de trabalho, antecipar problemas e evitar acidentes (Guérin et al., 2001), como sintetiza um dos entrevistados: "Essa segurança vem através da experiência". Entretanto, o rodízio eventual de funções, da forma como é realizado, não permite que os trabalhadores acumulem experiência suficiente sobre o trabalho $\mathrm{e}$ construam estratégias individuais e coletivas para evitar os acidentes de trabalho. Ao contrário, eles se preocupam com a presença de colegas novatos no setor, pois conhecem bem os riscos a que todos serão expostos, sobretudo quando seus pares não têm experiência.

6 A proposta teórico-metodológica da Clínica da Atividade, desenvolvida por Yves Clot (2006), oferece elementos importantes para se compreender os riscos a que ficam expostos os trabalhadores quando não podem partilhar e desenvolver a experiência de trabalho. Entretanto, não sendo possível a exposição dessa abordagem neste espaço, remetemos o leitor à obra de Y. Clot (2006; 2008) e, também, ao artigo de Lima (2007), que discute as contribuições da Clínica da Atividade para o campo da segurança no trabalho. 


\section{Análise das comunicações de acidentes de trabalho}

A análise de 35 CATs arquivadas pelo Sindifogos também foi realizada, a fim de se conhecer a natureza dos incidentes e das lesões que atingem esses trabalhadores. A partir dos dados obtidos, pode-se fazer algumas observações.

Em primeiro lugar, fica evidente que os empregadores não reconhecem e, por conseguinte, não notificam as doenças profissionais que atingem os pirotecnistas. Todas as CATs nas quais há indicativos de doenças ocupacionais foram emitidas pelo Sindifogos. Assim, se, por um lado, os distúrbios e as lesões causados pelo processo produtivo sequer são reconhecidos, por outro, também é verdade que as empresas não têm conseguido adotar medidas de prevenção eficazes. A abertura ou reabertura das CATs é realizada, na maior parte dos casos, por iniciativa da entidade sindical e não das empresas. Esse dado sugere uma subnotificação dos acidentes de trabalho.

O segundo aspecto cuja relevância é evidente para este estudo se refere aos dados informados por certas categorias da CAT: natureza da lesão; categoria segundo a Classificação Internacional de Doenças (CID-10); e parte do corpo atingida. A análise realizada mostrou que quase todos os acidentes são típicos, ou seja, ocorrem durante o processo produtivo, sendo mais frequentes aqueles que atingem dedos, mãos, punhos, braços e outros elementos dos membros superiores, o que é perfeitamente compreensível, já que são exatamente essas partes do corpo as mais utilizadas pelos operários. As amputações traumáticas de dedos e os traumatismos do punho, mãos, braços e antebraços estão entre os acidentes mais frequentes, totalizando 14 casos, ou seja, $40 \%$ das CATs analisadas. No que se refere às doenças identificadas, pode-se dizer que, em geral, são doenças do sistema osteomuscular e do tecido conjuntivo, tais como as tenossinovites e sinovites, num total de 13 casos, ou 37\% das CATs analisadas. As queimaduras causadas por fogo, chama ou material incandescente, juntamente com problemas no sistema respiratório causados por inalação de fumaça, respondem por $17 \%$ dos acidentes analisados (6 casos). Por último, as fraturas decorrentes de quedas de veículos representam $6 \%$ ( 2 casos). Todavia, os empregadores insistem em não reconhecer esses distúrbios e outros problemas decorrentes da produção, como doenças relacionadas ao trabalho.

Durante a análise das CATs, notou-se a utilização de uma ideologia da responsabilização, por parte das empresas, para explicar certos acidentes de trabalho. Observou-se, por exemplo, a seguinte explicação, dada por uma fábrica a um desses eventos:

\section{Comunicação de Acidente de Trabalho emitida em 2008}

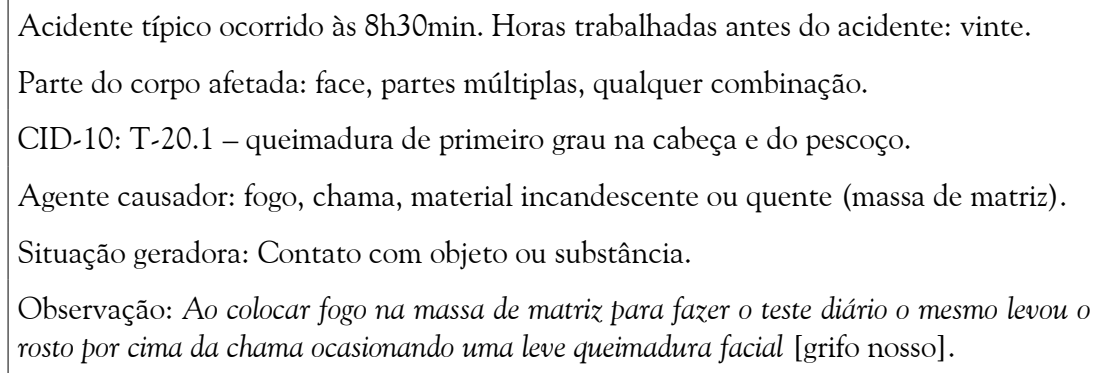

Será razoável acreditar que a trabalhadora teria levado seu rosto em direção ao fogo por mera imprudência? Não seria necessário indagar em que condições se encontrava a funcionária após 20 horas de trabalho, como registrado? Após 20 horas de trabalho, não seria, no mínimo, razoável pensar que os níveis de atenção e vigilância tenham declinado, em função da fadiga? E, ainda, que nessas circunstâncias ela passaria a realizar suas atividades quase que de forma automatizada, com reduzida capacidade para gerir situações adversas da produção? Não é difícil 
perceber que estamos diante da conhecida prática de responsabilização dos trabalhadores, quando da ocasião de acidentes de trabalho, já estudada por diversos pesquisadores (Vilela, Iguti \& Almeida, 2004). Nesses casos, as perícias e análises dos acidentes dispensam as análises dos fatores determinantes dos acidentes de trabalho, optando por buscar os culpados e atribuir a culpa às vítimas, sob o pretexto de atos inseguros. Trata-se de paradigma analítico fortemente marcado por um viés ideológico, cujos ganhos para os empresários foram bem resumidos pelo desembargador Sebastião Geraldo de Oliveira, do Tribunal Regional do Trabalho de Minas Gerais (3- Região). Ele afirma que quando se "constata" a culpa exclusiva da vítima, o empregador se livra do pagamento de qualquer indenização no campo da responsabilidade civil (Oliveira, 2010).

\section{As lesões por esforços repetitivos e as doenças osteomusculares relacionadas ao trabalho}

Os termos lesão por esforço repetitivo (LER) e doença osteomuscular relacionada ao trabalho (DORT) têm sido empregados para caracterizar um conjunto heterogêneo de patologias musculoesqueléticas, de origem ocupacional, que abrange, segundo Assunção e Vilela (2009, p. 20), doenças inflamatórias e degenerativas do aparelho locomotor, tais como:

- As inflamações dos tendões dos antebraços, punhos, ombros, em trabalhadores que realizam trabalho repetitivo e/ou adotam postura estática por exigência da tarefa;

- As mialgias, dores e perturbações funcionais dos músculos na região do ombro e pescoço, principalmente, em trabalhadores que adotam, por exigência da tarefa, posturas estáticas prolongadas nessa região;

- Compressão dos nervos na região do punho;

- Degenerações na coluna cervical.

Com frequência, esses distúrbios podem causar a incapacidade laboral temporária ou permanente (Instituto Nacional do Seguro Social, 2003), e, em geral, a dor, o desconforto e a fadiga são preditores importantes desses distúrbios, podendo ser associados pelos trabalhadores ao processo de trabalho, de forma mais ou menos explícita (Assunção \& Vilela, 2009). Como já se sabe, esses distúrbios se tornaram mais frequentes a partir da industrialização (Instituto Nacional do Seguro Social, 2003), em função das novas formas de organização da produção, sendo um equívoco grave considerá-los simulação ou resultado de conflitos psíquicos da personalidade dos indivíduos (Lima, 1998).

Quando se trata de LER/DORT, é necessário sublinhar que são distúrbios de origem multifatorial complexa e que envolvem um conjunto de fatores determinantes e de risco (Assunção \& Vilela, 2009). Os fatores de risco são aqueles que têm "o potencial de causar um efeito adverso, no caso, a dor musculoesquelética" (Assunção \& Vilela, 2009, p. 23). Enquanto, os fatores determinantes podem ser concebidos como aqueles que "geram uma situação ou fator de risco" (Assunção \& Vilela, 2009, p. 23). Os fatores de risco da LER/DORT são bem conhecidos pela literatura científica e se dividem, segundo Assunção e Vilela (2009, p. 21) em:

- Fatores biomecânicos (repetitividade dos gestos e movimentos, posições extremas, força e esforços físicos realizados, vibrações originadas de máquinas) ${ }^{7}$;

- Fatores organizacionais e psicossociais (organização do trabalho, fraco controle sobre o trabalho, pagamento por produção, ausências de pausas, insatisfação, percepção negativa do trabalho).

7 Por convenção, chama-se de trabalho repetitivo as atividades laborais cujo ciclo se completa em um tempo inferior a 30 segundos, ou trabalhos em que os movimentos repetitivos ocupem mais de $50 \%$ do tempo total (Lima, 1997). Pode-se considerar também como parâmetro para a caracterização do trabalho repetitivo, de acordo com o que é sugerido pela literatura pertinente, "a existência de um ciclo mais curto que dois minutos, o qual é repetido durante a jornada” (Assunção \& Vilela, 2009, p. 33). 
Por sua vez, Assunção e Vilela (2009) afirmam que as demandas de esforços físicos intensos e a repetitividade de gestos e movimentos são originadas por fatores econômicos e organizacionais, que, por isso, podem ser considerados determinantes de LER/DORT. Na mesma direção, Lima (1997) enfatiza o equívoco de considerar na origem da LER/DORT apenas os fatores biomecânicos. Para ele, a organização do trabalho constitui a determinação essencial de LER/DORT, uma vez que é a forma de divisão, organização e gerenciamento do trabalho que submete as pessoas a ser apêndices das máquinas, tendo de trabalhar em ritmos ditados por processos automáticos. Portanto, a intensificação do trabalho não pode ser atribuída às máquinas, mas aos ritmos de trabalho impostos pela organização do trabalho, materialização do controle do capital sobre o trabalho e fator determinante de LER/DORT (Lima, 1997).

Assim, as LERs/DORTs resultam "de um desequilíbrio entre as exigências das tarefas realizadas no trabalho e as capacidades funcionais individuais para responder a essas exigências", sendo que esses desequilíbrios "são modulados pelas características da organização do trabalho, a qual constitui alvo das medidas de transformação das condições geradoras do adoecimento" (Assunção \& Vilela, 2009, p. 20).

No caso do setor pirotécnico, o desequilíbrio entre as exigências da produção e a capacidade funcional dos trabalhadores para poder enfrentá-las é explícita. Mesmo nos setores onde não há máquinas, eles estão submetidos à intensificação dos ritmos de trabalho, determinados por fatores organizacionais (divisão das tarefas, normas e metas de produção, mecanismos de controle da produção) e psicossociais (medo, insatisfação, monotonia, perda do sentido do trabalho, ameaça ao emprego, violência moral etc.). Por tudo isso, pode-se dizer que seu trabalho é penoso e nocivo, pois "as margens postas pela organização do trabalho constrangem o trabalhador e reduzem suas possibilidades de construção da saúde" (Assunção \& Lima, 2002, p. 1769) ${ }^{8}$. No processo produtivo dos fogos de artifício pode-se perceber que os fatores de risco de natureza ocupacional das LERs/DORTs estão sempre presentes, a saber: posição forçada; ritmo de trabalho penoso; e condições difíceis de trabalho. Por isso, as dores nos punhos e membros superiores ocupam lugar de destaque no depoimento dos profissionais, sobretudo daqueles que trabalham em etapas da produção caracterizadas pela repetitividade dos gestos e movimentos, como, por exemplo, arrematação de fogos, espoletação, rotulação, fabricação de munição e explosivos, cartonagem, matriz e carregamento: "Sente dor demais! Tem dia que tem que tomar remédio se não você não dá conta de fazer tarefa, não. A maioria das pessoas de fábrica toma remédio diariamente, porque não dá conta, não, de fazer a tarefa, sabe?".

Há vários relatos sobre os agravos à saúde, decorrentes de jornadas de trabalho longas e desgastantes. As lesões por esforços repetitivos, sobretudo, fazem parte desse quadro de patologias profissionais, o que é confirmado pela análise das CATs e das verbalizações dos trabalhadores:

Meu braço aqui [antebraço] já dói, tem 9 anos que eu trabalho com isso, meu braço eu já sinto... Ah, tem hora que fica dormente, dói assim, sabe, eu fui no médico uma vez sabe, ele falou que isso já era início de LER, DORT.

No caso dos pirotecnistas, a LER/DORT atinge principalmente os elementos dos membros superiores, tais como: mãos, punhos e ombros. Essas lesões têm relação direta com o trabalho que realizam, como revela o seguinte depoimento:

É nessa atividade, nesse trabalho, como se diz, é muito tempo, né? Até pra uma máquina elétrica. Esse braço meu... eu sei que daqui a uns tempos, eu já tenho dificuldade com ele, e daqui uns tempos eu posso perder o movimento todinho dele. Sabe quando você fica

80 reconhecimento do caráter penoso do trabalho resulta da análise da percepção subjetiva dos trabalhadores em relação à sua tarefa e aos riscos a que estão expostos (Assunção \& Lima, 2002). Com essa concepção, não se considera apenas "a exposição aos riscos" e o "corpo do trabalhador", numa relação unívoca (Assunção \& Lima, 2002). 
fazendo assim com a mão [abrindo e fechando], porque tá muito tensa, até mesmo porque o ombro dá aquela dor, assim... Então, eu fico fazendo isso com a mão direto, porque minha mão fica tensa direto, aqui, oh. Tem de tá fazendo assim [abrindo e fechando a mão], oh, porque fica repuxando, sabe? Eu tenho que tá fazendo assim.

Os distúrbios são provocados por atividades de trabalho que exigem movimentos repetitivos, contínuos, rápidos e/ou vigorosos, realizado em curtos ciclos, durante a maior parte da jornada de trabalho (Assunção, 2006):

E meu braço, aqui [antebraço], hoje mesmo tava comentando com a minha colega de trabalho, tem um negócio aqui, oh, passa a mão aqui pra você ver, um carocinho, tá vendo? Isso dói que queima, e aqui também tá doendo. Isso aqui eu já acho que é o nervo que deve ter arrebentado ou alguma coisa aqui, porque esse aqui tem hora que fica inchado sabe? Igual agora, ele parou de doer, mas na hora que eu tô trabalhando ele me atrapalha sempre.

Como já foi dito, a pressão dos encarregados das fábricas, traduzida pela supervisão e ameaças de desconto no salário e exigências de produtividade, cumprem um papel importante no surgimento das lesões por esforços repetitivos. O conteúdo do trabalho é, quase sempre, o mesmo e os trabalhadores permanecem até seis horas por dia executando os mesmos movimentos. A monotonia e o empobrecimento do conteúdo significativo do trabalho (Lima, 1998) também trazem consequências à saúde dos operários. Como relatado, as dores nos punhos, mãos, antebraços e braços, ocasionadas pelo intenso ritmo de trabalho e pela repetitividade dos gestos, somada à pressão exercida pelos superiores, atingem não só o desempenho do trabalhador, mas outras esferas de sua vida, que ficam comprometidas em virtude desse trabalho:

Eu não tenho coordenação na minha mão, não. Por exemplo, se eu for lavar um copo lá em casa, na hora em que eu tô lavando vasilha, eu não tenho força na minha mão pra pegar um copo, então cai, sabe, eu não tenho a mesma força que eu tenho nesta, entendeu?

Além do relato dessa trabalhadora, outros que exercem a mesma função também verbalizam já ter vivenciado situações semelhantes ou conhecem alguém que já foi vítima desse problema, por trabalhar na fabricação de fogos de artifício.

Igual teve uma colega minha que perdeu o movimento todinho do braço, ela teve de fazer cirurgia... Ela perdeu o movimento todinho do braço e teve de fazer várias cirurgias, ela trabalhava na mesma fábrica que eu..., ela tá afastada, aí. No caso, eu sei que futuramente vai acontecer comigo o mesmo que tá acontecendo com ela, mas, por enquanto, eu não posso largar.

As pausas não são toleradas pelos encarregados ou patrões, porque atrasam a produção, o que leva a uma sobrecarga da estrutura anatômica do sistema osteomuscular e na falta de tempo para sua recuperação. Assim, quem sofre as consequências desse processo são os operários, o que fica evidenciado em todos os depoimentos coletados:

Ah, isso daqui [problemas e dores no antebraço] deve ter uns dois, três anos, já. Só que tem hora que ele incha muito mais, tem hora que não incha, não. Só que ele queima, é, tipo assim, como se fosse uma linha aqui dentro, dentro do osso aqui, oh, como se uma linha que vai daqui até aqui puxando como se tivesse uma linha de carretel puxando e queima, parece que tá aqui dentro, aqui, parece que tem uma agulha, daqui até aqui. 
O fato de ir ao médico buscar tratamento para as lesões pode significar a perda do emprego, pois, segundo afirmam, "nenhum patrão quer manter um funcionário doente":

Ela levou atestado pra trocar de função, assim que ela entregou o resultado lá pra moça de relações humanas, é... como que fala? Recursos humanos... a moça deu férias pra ela, deu férias pra ela de 35 dias, provavelmente, são as férias que ela tem na empresa, quando ela voltar é capaz de eles mandarem ela embora, entendeu?

As fábricas não toleram trabalhadores com problemas de saúde que, como indicado, resultam do próprio processo produtivo. O sentimento de injustiça é experimentado por esses operários cotidianamente e, sobretudo, nas situações em que são discriminados pelas empresas em função de seu estado de saúde.

\section{Considerações finais}

Os resultados obtidos por este estudo revelam que os trabalhadores do setor pirotécnico estão expostos a uma série de fatores de risco à sua saúde e segurança no contexto laboral. Os acidentes de trabalho, quase sempre fatais ou mutilantes, encontram-se entre os problemas mais graves existentes nesse segmento produtivo, semeando entre os pirotecnistas a tensão e o medo de trabalhar.

O exercício de atividades para as quais não foram devidamente treinados (em termos teóricos e práticos) põe em risco a vida dos operários. Os efeitos da fadiga decorrente das jornadas de trabalho extenuantes também devem ser considerados fatores de risco, pois reduzem, indiscutivelmente, as possibilidades de se proteger desses incidentes, minimizando seu controle sobre o processo produtivo.

O caráter monótono e repetitivo das tarefas, o ritmo de trabalho penoso, a ausência de pausas, as longas jornadas de trabalho, somados às pressões por produção e supervisão exercidas pelas empresas, contribuem consideravelmente para a sobrecarga musculoesquelética dos membros superiores e, consequentemente, para o aparecimento de lesões por esforços repetitivos (LERs) e doenças osteomusculares relacionadas ao trabalho (DORTs).

Pode-se dizer, portanto, que, no decorrer de suas atividades profissionais, esses trabalhadores estão sujeitos às explosões e outros acidentes de trabalho típicos nesse setor. Em particular, as mulheres que trabalham no setor pirotécnico, enfrentam, ainda, o assédio sexual praticado pelos encarregados e raramente encontram apoio e/ou respaldo jurídico para evitar essas situações, tendo de se submeter a elas para não perder o emprego. Dessa forma, se, por um lado, a indústria de artigos pirotécnicos é tratada como um patrimônio da cidade, por outro, os fogos de artifício, que tanto encantam as pessoas em festividades, têm custos e significados distintos para os cidadãos de Santo Antônio do Monte e, principalmente, para os operários que fabricam esses produtos.

Por ser tratar de um estudo exploratório e, ainda, pelas dificuldades que permearam sua realização (composição da equipe, questões logísticas etc.), não foi possível abordar todas as etapas do processo produtivo, tampouco realizar as observações das situações reais de trabalho e sua análise minuciosa, como foi pretendido inicialmente. Todavia, se se quiser aprofundar as análises aqui expostas e propor medidas de melhoria das condições de trabalho e saúde mais específicas, a análise de cada etapa da produção de fogos de artifício e das situações reais de trabalho constitui uma tarefa incontornável. Não tendo sido possível realizá-la, este artigo se propôs a levantar questões importantes sobre as condições de trabalho dos pirotecnistas, que já 
podem servir para a elaboração de medidas preventivas no campo da saúde e segurança no trabalho'.

\section{Referências}

Associação Brasileira de Pirotecnia. (2010). História no Brasil. Recuperado em 10 de maio, 2010, de http://www.assobrapi.com.br/brasil.htm.

Assunção, A. A. (2003). Uma contribuição ao debate sobre as relações saúde e trabalho. Ciência Ė Saúde Coletiva, 8 (4), 1005-1018.

Assunção, A. A. (2006). Ciclos curtos e repetitivos de trabalho: o caso de uma fábrica de metais. In R. Antunes (Org.), Riqueza e miséria do trabalho no Brasil (pp. 177-188). São Paulo: Boitempo.

Assunção, A. A., Lima, F. P. A. (2002). A contribuição da ergonomia para identificação, redução e eliminação da nocividade do trabalho. In R. Mendes (Org.), Patologia do trabalho (pp. 1767-1789). São Paulo: Atheneu.

Assunção, A. A. \& Vilela, L. V. O. (2009). Lesões por esforços repetitivos: guia para profissionais de saúde. Piracicaba, SP: Centro de Referência em Saúde do Trabalhador.

Brasil. (2000). Decreto n. 3.665, de 20 de novembro de 2000 (2000, 21 de novembro). Dá Nova Redação ao Regulamento para Fiscalização de Produtos Controlados (r-105). Diário Oficial da União, seção 1. Recuperado em 10 de setembro, 2010, de http://br.vlex.com/vid/nova-regulamento-produtos-controlados-34332859.

Clot, Y. (2006). A função psicológica do trabalho. Petrópolis, RJ: Vozes.

Clot, Y. (2010). Trabalho e poder de agir. Belo Horizonte: Fabrefactum.

Engels, F. (1844/2008). A situação da classe trabalhadora na Inglaterra. São Paulo: Boitempo.

Gorz, A. (1996). O despotismo de fábrica e suas consequências. In K. Marx, Crítica da divisão do trabalho (pp. 81 89). São Paulo: Martins Fontes.

Guérin, F., Laville, A., Daniellou, F., Duraffourg, J. \& Kerguelen, A. (2001). Compreender o trabalho para transformálo: a prática da ergonomia. São Paulo: Edgar Blücher.

Instituto Nacional do Seguro Social. (2003). Instrução Normativa n. 98, de 2003. Recuperado em 8 de fevereiro, 2011, de http://www81.dataprev.gov.br/sislex/imagens/paginas/38/inss-dc/2003/anexos/IN-DC-98-ANEXO.htm.

Le Guillant, L. (2006). Escritos de Louis Le Guillant da Ergoterapia à Psicopatologia do Trabalho. Petrópolis, RJ: Vozes.

Lima, F. P. A. (1997). Noções de organização do trabalho. In C. R. Oliveira, Manual prático de L. E. R. (pp. 167189). Belo Horizonte: Health.

Lima, M. E. A. (1998). A dimensão psicológica. In J. N. G. Araújo, F. P. A. Lima \& M. E. A. Lima (Orgs.), Lesões por esforços repetitivos - L. E. R.: dimensões ergonômicas e psicossociais. Belo Horizonte: Health.

Lima, M. E. A. (2007). Contribuições da Clínica da Atividade para o campo da segurança no trabalho. Revista Brasileira de Saúde Ocupacional, 32 (115), 99-107.

Minayo, M. C. S. (1994). O desafio do conhecimento: pesquisa qualitativa em saúde. São Paulo: Hucitec.

Ministério da Previdência Social. (2006). Anuário Estatístico de Acidentes de Trabalho. Recuperado em 10 de novembro, 2010, de http://mpas.gov.br/arquivos/office/3_081013-161951-251.pdf.

Ministério da Previdência Social. (2007). Anuário Estatístico de Acidentes de Trabalho. Recuperado em 10 de novembro, 2010, de http://mpas.gov.br/arquivos/compressed/3_081209-173950-588.zip.

Ministério da Previdência Social. (2008). Anuário Estatístico de Acidentes de Trabalho. Recuperado em 10 de novembro, 2010, de http://mpas.gov.br/arquivos/office/3_091028-191015-957.pdf.

Ministério do Trabalho e Emprego (2000a). Classificação Brasileira de Ocupações - CBO. Recuperado em 10 de julho, 2010, de http://www.mtecbo.gov.br/cbosite/pages/downloads.jsf.

Ministério do Trabalho e Emprego. (2000b). Norma Regulamentadora n. 19. Recuperado em 10 de março, 2010, de http://www.mte.gov.br/legislacao/normas_regulamentadoras/nr_19.pdf.

9 Um documento com recomendações para a melhoria das condições de trabalho, saúde e segurança foi entregue ao Sindifogos, em dezembro de 2010. 
Oliveira, S. G. (2010). Proteção jurídica à saúde do trabalhador. São Paulo: LTr.

Outra Explosão com fogos de artifício em Santo Antônio do Monte. (2011). Recuperado em 8 de fevereiro, 2011, de http://megaminas.globo.com/2010/07/29/outra-explosao-com-fogos-de-artificio-em-santo-antonio-do-monte.

Prefeitura Municipal de Santo Antônio do Monte. (2010). Dados demográficos. Recuperado em 10 de maio, 2010, de http://www.samonte.mg.gov.br/subarea.php?subarea $=3$.

Santos, E. M. M. (2007). O trabalhador pirotécnico de Santo Antônio do Monte e seu convívio diário com o risco de acidente súbito. Dissertação de Mestrado, Programa de Pós-graduação em Psicologia, Pontifícia Universidade Católica de Minas Gerais, Belo Horizonte.

Trivelato, G. da C. \& Barreto, J. M. A. (2008). Prevenção de explosões na fabricação de fogos de artifício no arranjo produtivo de Santo Antônio do Monte. In Semana de Pesquisa. Belo Horizonte: Fundacentro.

Vieira, C. E. C., Lima, F. P. A. \& Barros, V. A. (2007). A abordagem da Psicologia do Trabalho na presença do trabalho. Psicologia em Revista, 13 (1), 155-168.

Vilela, R. A. G., Iguti, A. M. \& Almeida, I. M. (2004). Culpa da vítima: um modelo para perpetuar a impunidade nos acidentes do trabalho. Cadernos de Saúde Pública, 20 (2), 570-579.

\section{Endereço para correspondência}

carloseduardo_carrusca@yahoo.com.br,ac.oliveira@yahoo.com.br, rafaelacouto-psicologia@hotmail.com,ionaralvespsi@hotmail.com 